\title{
ENSINO, APRENDIZAGEM, RELAÇÕES SOCIAIS E OS CONFLITOS NA ESCOLA: IMPLICAÇÕES COM O CLIMA ESCOLAR
}

\author{
Carmen Lúcia Dias \\ Universidade do Oeste Paulista - UNOESTE, Mestrado em Educação, Presidente Prudente, SP. E-mail: \\ kkaludias@gmail.com.
}

\begin{abstract}
RESUMO
Este artigo, integrado a um projeto de pós-doutorado e pesquisa docente objetiva propor uma reflexão sobre o clima escolar e suas implicações com o ensino, aprendizagem, as relações sociais e os conflitos na escola. O clima escolar pode ser entendido como um conjunto de percepções em relação à instituição de ensino que, em geral, descortinam os fatores relacionados à organização, às estruturas pedagógica e administrativa, além das relações humanas que ocorrem no espaço escolar. Esta pesquisa se apoiou em revisão de literatura especializada (SEVERINO, 2007; BENTO, 2012), com a utilização de descritores nas Bases de dados ERIC; SIBiUSP; SciELO ; Portal de Periódico CAPES/MEC; Portal Domínio Público; Sage Journals; Portal OASISBR; Open Access Theses and Dissertations - OATD. As pesquisas apontam as implicações positivas do clima escolar e a sua interlocução com a escola quanto ao ensino- aprendizagem, o rendimento escolar e nas relações humanas que ocorrem no espaço escolar.
\end{abstract}

PALAVRAS-CHAVE: Ensino-Aprendizagem. Relações sociais e conflitos na escola. Clima escolar. Educação Básica.

TEACHING, LEARNING, SOCIAL RELATIONS AND CONFLICTS IN SCHOOL: IMPLICATIONS WITH THE SCHOOL CLIMATE

\begin{abstract}
This article, which is part of a postdoctoral project and teacher research, aims to reflect on the school climate and its implications for teaching, learning, social relations and conflicts in school. The school climate can be understood as a set of perceptions regarding the educational institution, which, in general, reveal the factors related to the organization, the pedagogical and administrative structures, as well as the human relations that occur in the school space. This research was supported by a review of specialized literature (SEVERINO, 2007; BENTO, 2012), with the use of descriptors in the ERIC Databases; SIBiUSP; SciELO; CAPES / MEC Newspaper Portal; Public Domain Portal; Sage Journals; Portal OASISBR; Open Access Theses and Dissertations OATD. The researches point out the positive implications of the school climate and its interlocution with the school regarding teaching-learning, school performance and human relations that occur in the school space.
\end{abstract}

KEYWORDS: Teaching-Learning. Social relations and conflicts in school. School climate. Basic education. 


\section{INTRODUÇÃO}

A relação entre as pessoas tem sido causa de muitas situações conflitantes em nossa sociedade. Essas situações são vividas de forma ampla, quer seja no trânsito, no trabalho, na escola e no cotidiano de maneira geral. A preocupação de pais, professores e de especialistas em educação traz para a escola alguns pontos a serem pensados. Questionamentos sobre a função de se tratar temas que abarcam a tarefa de formar moralmente as crianças e jovens que frequentam as escolas; episódios agressivos que permeiam os espaços escolares; a indisciplina e a violência utilizadas como recurso para se resolver problemas e por fim, as velhas ações comumente aplicadas advertências, suspensões, parecem não resolver as situações de desrespeito na escola atual.

É dever da escola educar moralmente os jovens? Desde o fim do regime militar em que o sistema educacional estava a serviço da transmissão de valores dominantes (FREITAG, 1980), reiniciou-se o debate sobre a educação e de acordo com a Constituição Federal de 1988, em seu artigo 30 (BRASIL, 1988), afirmou a educação como um direito de todos e dever do Estado e da família e, mesmo nesta nova perspectiva manteve-se a disciplina Educação Moral e Cívica no currículo oficial, resquício do período ditatorial anterior. No final da década de 1990 surgiram os Parâmetros Curriculares Nacionais ou PCNs, trazendo os Temas Transversais: Ética, Meio Ambiente, Pluralidade Cultural, Saúde e Orientação Sexual, Trabalho e Consumo. La Taille (2009) explica que o termo "transversalidade" não é novo na educação e citando Piaget "é preciso distinguir o procedimento que consiste em não dar um lugar especial à moral no horário das aulas, mas em empregar os diferentes ramos do ensino para se livrar a considerações morais atinentes a eles" (LA TAILLE, 2009, p. 251). Esses temas deveriam ser trabalhados em sala de aula, juntamente com temas sociais diversos tratados por todos os professores, partindo dos conteúdos de suas respectivas matérias. No tema Ética, a proposta caminha na direção de que "cabe à escola empenhar-se na formação moral de seus alunos" (BRASIL, 2000, p. 73), assegurando ser essa proposta "diametralmente diferente das antigas aulas de Moral e Cívica" (CAMINO; PAZ; LUNA, 2009, p. 132), que tem por conteúdos o respeito mútuo, justiça, diálogo e solidariedade.

De acordo com Piaget,

o principal objetivo da educação é criar homens que sejam capazes de fazer coisas novas, e não simplesmente repetir o que outras gerações já fizeram - homens que sejam criativos, inovadores e descobridores. 0 segundo objetivo da educação é formar mentes que possam ser críticas, possam verificar, e não aceitar o que lhes é oferecido. (PIAGET, 1964, p.7).

Diante disto, como poderemos "formar estes homens", num regime onde prevalecem as situações conflitantes, as relações heterônomas, a falta de respeito, solidariedade e justiça? Ainda de Piaget (1944, p.1), na construção da inteligência o pensamento supõe o jogo livre das funções intelectuais e não o trabalho sob pressão. "É preciso ensinar os alunos a pensar, e é impossível aprender a pensar num regime autoritário. Pensar é procurar por si próprio, é criticar livremente e é demonstrar de forma autônoma".

De acordo com o autor, observamos que a construção da inteligência supõe a interação com o objeto de conhecimento, relações de cooperação entre aluno e professor, a relação entre pares; um ambiente democrático com trocas onde prevaleçam a cooperação, o respeito mútuo e o diálogo. E é na escola que essas oportunidades devem ser vivenciadas.

Nesta linha de pensamento concordamos com o relatório da Organização para a Cooperação e o Desenvolvimento Econômico- OCDE (OCDE, 1992, p. 114) sobre a Qualidade de ensino diz que "todas as crianças e jovens precisam de um ambiente tanto seguro quanto estimulante". Para que isso aconteça, um olhar sobre a constituição do ambiente escolar deverá ser mantido, ou seja, este é permeado por grupos que se organizam e interagem entre si. As 
relações que se estabelecem neste contexto que envolve a organização, as estruturas pedagógicas e as relações humanas, compõem o clima escolar (VINHA, 2014).

Sob essa perspectiva este artigo tem por objetivo propor uma reflexão sobre o clima escolar e suas implicações com o ensino, aprendizagem, as relações sociais e os conflitos na escola.

\section{METODOLOGIA}

Esta pesquisa se apoiou em uma revisão de literatura especializada sobre o clima escolar (SEVERINO, 2007; BENTO, 2012), com a utilização de descritores ("clima escolar", "el clima escolar", "school climate", "le climat scolaire") nas Bases de dados ERIC; SIBiUSP; SciELO - Scientific Eletronic Library Online; Portal de Periódico CAPES/MEC; Portal Domínio Público; Sage Journals; Portal Brasileiro de Acesso Aberto à Informação Científica - OASISBR; Open Access Theses and Dissertations - OATD.

\section{DISCUSSÃO}

As pesquisas sobre clima escolar na Educação Básica, são reconhecidas nacional e internacionalmente. No decurso das últimas três décadas é possível constatar o interesse crescente por parte de pesquisadores, organizações e escolas de diferentes países com relação à essa temática por suas implicações significativas com a relação ensino-aprendizagem; com o desempenho escolar e as relações interpessoais que nesse ambiente ocorrem.

O clima escolar pode ser entendido como um conjunto de percepções em relação à instituição de ensino que, em geral, descortinam os fatores relacionados à organização, às estruturas pedagógica e administrativa, além das relações humanas que ocorrem no espaço escolar. E, de forma geral, este é avaliado por instrumentos para avaliar as percepções dos sujeitos (gestores, professores, alunos etc.) que são compostos por dimensões, tais como Ensino e Aprendizagem; As relações sociais e os conflitos na escola; As regras, as sanções e a segurança na escola; A família, a escola e a comunidade; As relações com o trabalho; A gestão e a participação.

Estudos sobre o clima escolar apontam uma pluralidade de definições, porém, todos têm em comum a ideia de "clima como percepção dos indivíduos sobre o ambiente circundante e tem demonstrado que a forma como os indivíduos percebem coletivamente essa 'atmosfera' traz significativas influências sobre o comportamento dos grupos." (BRITO; COSTA, 2010, p. 501).

Citando Fox, Cunha e Costa (2009) colocam que

o clima de uma escola resulta do tipo de programa, dos processos utilizados, das condições ambientes que caracterizam a escola como uma instituição e como um agrupamento de alunos, dos departamentos, do pessoal e dos membros da direção. Cada escola possui o seu clima próprio. O clima determina a qualidade de vida e a produtividade dos docentes e dos alunos. O clima é um fator crítico para a saúde e para a eficácia de uma escola. (CUNHA; COSTA, 2009, p. 12-13).

Convém destacar que o clima é uma variável subjetiva e relaciona-se com a percepção e os sentimentos vivenciados e partilhados entre as pessoas a partir de um contexto real, ou seja, os elementos que compõem o clima escolar são variados. Não há um único fator determinante, mas sim a interação de vários fatores intrínsecos à escola. Não obstante ouvir as vozes e percepções de todos os atores, de acordo com Oesselmann (2009), é uma maneira de se levantar dados e apreender realidades complexas que perfazem o clima escolar.

São relatados em estudos sobre o clima escolar aspectos que investigam o desempenho acadêmico dos alunos como os de Canguçú e Romero (2013); Jankens (2011) dentre outros; mas vale ressaltar que existem estudos, de acordo com Rutter et al. (2008) que privilegiam também 
fatores comportamentais. Ainda os autores destacam que nas escolas em que o clima escolar é positivo, funcionários e alunos tendem a ser mais motivados e satisfeitos, convivendo em ambientes seguros e acolhedores.

Na pesquisa de Haselswerdt e Lenhardt (2003) que tem como tema a violência escolar, os autores puderam verificar que em ambientes em que os alunos não tendo a liberdade suficiente para manifestarem suas percepções e opiniões, prospecta-se um clima escolar insensível, propenso a episódios de violência escolar. Outro ponto importante destacado pelos autores, como possível fator responsável pelo aumento dessa violência, deve-se à desarticulação dos membros da comunidade escolar. O que referenda Casassus (2007) quando aponta que, por meio de seus estudos realizados nessa temática, a existência de boas relações interpessoais entre todos os membros da comunidade escolar, refletem num clima escolar positivo com melhores resultados quanto ao desempenho escolar.

Outro pesquisador, Stewar (2008), promoveu um estudo em 715 escolas de Ensino Médio na Flórida, com o objetivo de investigar as influências individual e características estruturais escolares associadas ao desempenho acadêmico, utilizando uma estrutura de vários níveis em uma amostra nacional de estudantes. A amostra foi abstraída do banco de dados do National Longitudinal Study Educational (NELS). Três dimensões do ambiente escolar foram o foco central: Cultura escolar (centra-se nas crenças, valores, atitudes e várias situações de interação entre alunos, professores e corpo administrativo); Estrutura organizacional da escola (em grande parte medida pela classe e pelo tamanho da escola); Ambiente social da escola (refere-se às características dos alunos, professores e administradores, envolvendo também etnia, gênero, status socioeconômico, experiência e formação dos professores). Os dados coletados sobre características a nível individual (esforço do aluno, pertencimento à escola, motivação escolar, diálogo entre pais e filhos e a associação entre pares positivos) basearam-se em relatórios do estudante. Administradores, professores e alunos forneceram informações sobre os diversos aspectos da escola. A conclusão do estudo é que houve associação significativa entre os preditores de nível individual e o desempenho acadêmico, percebido também em relação aos preditores estruturais da escola e a coesão escolar com significância em relação ao desempenho escolar.

Portanto, para conhecer o clima de uma escola é preciso investigar o conjunto de percepções em relação à instituição pelos seus integrantes.

Assim, ouvir falas e percepções de todos os atores, como gestores, professores, alunos, pais é uma forma de se obter dados e apreender realidades complexas que perfazem o clima escolar.

\section{CONCLUSÃO}

Nesta breve exposição podemos observar pelas pesquisas, o que apontam sobre as implicações do clima escolar e a sua interlocução com a escola quanto à sua organização, estrutura pedagógica e administrativa e, mais especificamente suas implicações com o processo de ensino e de aprendizagem e nas relações humanas que ocorrem no espaço escolar, com vistas à um clima escolar harmônico, onde se cultivem as relações democráticas como o respeito, a solidariedade, a cooperação, a autonomia intelectual e moral.

Depreende-se das pesquisas realizadas sobre o clima escolar que estas envidam esforços para que cada vez mais se avancem em resultados comprovados empiricamente, porém, ainda o clima escolar é um tema que precisa ser muito explorado, estudado e debatido entre pesquisadores e todos os envolvidos da comunidade escolar.

É relevante que se pense nesse cenário investigando o interior da escola. Assim, esperase que esses estudos possam contribuir para a ampliação de pesquisas sobre o clima escolar oferecendo à instituição escolar subsídios importantes sobre um conjunto de percepções que tratam do conhecimento da sua realidade escolar quanto à sua organização, estrutura pedagógica 
e administrativa e das relações humanas que nela ocorrem, podendo traçar estratégias de intervenção para que se ofereça uma educação de qualidade e de relações democráticas.

\section{REFERÊNCIAS}

BENTO, A. V. Como fazer uma revisão da literatura: considerações teóricas e práticas. Revista JÁ, Portugal: Associação Acadêmica da Universidade da Madeira, n. 65, ano VII, mai.2012.Disponívelem:http://www3.uma.pt/bento/Repositorio/Revisaodaliteratura.pdf. Acesso em: 21 ago.2014.

BRASIL. Constituição da República Federativa do Brasil. Diário Oficial da União, n. 191-A, 05 de outubro de 1988.

BRASIL. Ministério da Educação. Secretaria de Educação Fundamental (SEF). Parâmetros Curriculares Nacionais: apresentação dos temas transversais. Rio de Janeiro/ DP\&A, 2000. v. 8: Ética.

BRITO, M. de S. T.; COSTA, M. da. Práticas e percepções docentes e suas relações com o prestígio e clima escolar das escolas públicas do município do Rio de Janeiro. Revista Brasileira de Educação, v. 15, n. 45, set./dez. 2010. Disponível em: www.scielo.br/pdf/rbedu/v15n45/08.pdf.

CAMINO, C.; PAZ, M.; LUNA, V. Valores morais no âmbito escolar: uma revisão dos valores apresentados nos livros didáticos e por professores, de 1970 a 2006. In: LA TAILLE, Y.; MENIN, M. S.; SHIMIZU, A. M. [et al.]. Crise de valores ou valores em crise? Porto Alegre: Artmed, 2009.

CANGUÇÚ, L. A.; ROMERO, J. A. R. Estudos dos Condicionantes do Clima Escolar com Alunos do Ensino Fundamental das Escolas Públicas de Minas Gerais. ANAIS VII Reunião da ABAVE Avaliação e Currículo: um diálogo necessário, n. 1, Ano 2013 p. 109-128. Disponível em:

http://abave.com.br/ojs/index.php/abave/article/view/16

CASASSUS, J. A escola e a desigualdade. Unesco, 2007.

CUNHA, M. B.; COSTA, M. O clima escolar de escolas de alto e baixo prestigio. In: Reunião da Associação Nacional de Pós-Graduação e Pesquisa em Educação, 32., Anais... 2009, Caxambu-MG. Sociedade, cultura e educação: novas regulações, 2009.

FREITAG, B. Escola, estado e sociedade. São Paulo: Moraes, 1980.

LA TAILLE, Y. de. Formação ética: do tédio ao respeito de si. Porto Alegre: Artmed, 2009.

HASELSWERDT, M. V.; LENHARDT, A. C. Reframing school violence: listening to voices of students. The Educational Forum, v. 67, 2003, https://doi.org/10.1080/00131720308984581.

JANKENS, B. P. An Examination of the Relationship Between School Climate and Student Growth in select Michigan Charter Schools. Dissertation (Doctor of Education) - Eastern Michigan University, Ypsilanti, Michigan, 2011.

OCDE. Escuelas y calidad de la enseñanza. Paidós, Barcelona, 1992.

OESSELMANN, D. Clima escolar / Dirk Oesselmann (Coord.). Belém: Unama, 2009. 62 p. 
PIAGET, J. A Educação da liberdade. Tradução de Telma Pileggi Vinha. Conferência apresentada no 28o Congresso Suíço dos professores, em 08/07/44, em Berna. mimeo.

PIAGET, J. Development and learning In: RIPLE R. e Rockcastle U. Ithaca Piaget Rediscovered. Nova York: Cornel University Press, 1964.p. 7-20.

RUTTER, M. et al. Fifteen thousand hours: secondary schools and their effects on children. In: BROOKE, N.; SOARES, J. F. (Orgs.). Pesquisa em eficácia escolar: origem e trajetórias. Belo Horizonte: Ed. UFMG, 2008. p. 142 a 15; 163 a 186.

SEVERINO, A. J. Metodologia do trabalho científico. São Paulo: Cortez, 2007.

STEWAR, E. B. School Structural Characteristics, Student Effort, Peer Associations, and Parental Involvement: The Influence of School- and Individual-Level Factors on Academic Achievement. Education and Urban Society, v. 40, n. 2, p.179-204, January 2008, https://doi.org/10.1177/0013124507304167.

VINHA, T. P. Em busca de caminhos que promovam a convivência respeitosa em sala de aula todos os dias. Projeto de pesquisa. Unicamp/Lemann/Itau BBA. Campinas, 2014. 